University of Nebraska - Lincoln

DigitalCommons@University of Nebraska - Lincoln

USDA National Wildlife Research Center - Staff Publications
U.S. Department of Agriculture: Animal and Plant Health Inspection Service

2016

\title{
Development of artificial bait for brown treesnake suppression
}

\author{
Bruce A. Kimball \\ USDA-APHIS-WS-National Wildlife Research Center, bruce.kimball@ars.usda.gov
}

Scott A. Sterling

United States Department of Agriculture, Animal and Plant Health Inspection Service, Wildlife Services, National Wildlife Research Center

Thomas W. McAuliffe

United States Department of Agriculture, Animal and Plant Health Inspection Service, Wildlife Services, National Wildlife Research Center

Randal S. Stahl

USDA-APHIS-Wildlife Services, randal.s.stahl@aphis.usda.gov

Rafael A. Garcia

USDA-ARS, rafael.garcia@ars.usda.gov

See next page for additional authors

Follow this and additional works at: https://digitalcommons.unl.edu/icwdm_usdanwrc

Part of the Life Sciences Commons

Kimball, Bruce A.; Sterling, Scott A.; McAuliffe, Thomas W.; Stahl, Randal S.; Garcia, Rafael A.; and Pitt, William C., "Development of artificial bait for brown treesnake suppression" (2016). USDA National Wildlife Research Center - Staff Publications. 1783.

https://digitalcommons.unl.edu/icwdm_usdanwrc/1783

This Article is brought to you for free and open access by the U.S. Department of Agriculture: Animal and Plant Health Inspection Service at DigitalCommons@University of Nebraska - Lincoln. It has been accepted for inclusion in USDA National Wildlife Research Center - Staff Publications by an authorized administrator of DigitalCommons@University of Nebraska - Lincoln. 


\section{Authors}

Bruce A. Kimball, Scott A. Sterling, Thomas W. McAuliffe, Randal S. Stahl, Rafael A. Garcia, and William C. Pitt 


\title{
Development of artificial bait for brown treesnake suppression
}

\author{
Bruce A. Kimball • Scott A. Stelting • Thomas W. McAuliffe • \\ Randal S. Stahl · Rafael A. Garcia • William C. Pitt
}

Received: 12 May 2015/ Accepted: 24 November 2015/Published online: 14 December 2015

(C) Springer International Publishing Switzerland (outside the USA) 2015

This document is a U.S. government work and is not subject to copyright in the United States.

\begin{abstract}
The brown treesnake (Boiga irregularis) was accidentally introduced to Guam in the 1940s from the Admiralty Islands. A native of Australia, Papua New Guinea, and the Solomon Islands, the brown treesnake (BTS) continues to threaten the economy and ecology of Guam and is currently the subject of a cooperative program to control snake populations on the island and prevent its spread throughout the Pacific Rim. Delivery of toxic baits is a primary component of population suppression efforts. While many food items tested as baits for toxicant
\end{abstract}

Electronic supplementary material The online version of this article (doi:10.1007/s10530-015-1031-z) contains supplementary material, which is available to authorized users.

\section{B. A. Kimball ( $\square)$}

United States Department of Agriculture, Animal and Plant Health Inspection Service, Wildlife Services, National Wildlife Research Center, Monell Chemical Senses Center, 3500 Market Street, Philadelphia, PA 19104, USA

e-mail: bruce.a.kimball@aphis.usda.gov

\section{S. A. Stelting $\cdot$ R. S. Stahl}

United States Department of Agriculture, Animal and Plant Health Inspection Service, Wildlife Services,

National Wildlife Research Center, 4101 LaPorte Avenue, Fort Collins, CO 80521, USA

T. W. McAuliffe

United States Department of Agriculture, Animal and Plant Health Inspection Service, Wildlife Services,

National Wildlife Research Center, 210 Amau'ulu Road, P.O. Box 10880, Hilo, HI 96720, USA delivery provide relevant food prey cues leading to investigatory behaviors in BTS, only a few items tested in the past two decades have adequately promoted reliable consumption. Chief among them is the dead neonatal mouse (DNM). A series of chemical and bioassays were performed to identify materials with similar sensory qualities as DNM. Among the many items tested in a series of field experiments with free-ranging BTS in Guam, a processed meat product treated with an artificial mouse fat mixture was found to be removed from bait stations at rates greater than previously tested DNM substitutes and approaching removal rates of DNM. Furthermore, the test baits demonstrated excellent

\section{R. A. Garcia}

United States Department of Agriculture, Agricultural Research Service, Eastern Regional Research Center, Biobased and Other Animal Co-products Research Unit, 600 East Mermaid Lane, Wyndmoor, PA 19038, USA

W. C. Pitt

Smithsonian Conservation Biology Institute, 1500 Remount Road, Front Royal, VA 22630, USA 
durability under field conditions. Further development of this bait offers great potential to satisfy many desirable attributes for BTS baiting operations.

Keywords Boiga irregularis - Interdiction · Invasive $\cdot$ Pacific islands $\cdot$ Vertebrate

\section{Introduction}

The brown treesnake (Boiga irregularis) has caused extensive economic and ecological damage to Guam following its introduction from the Admiralty Islands subsequent to World War II, likely in military cargo (Rodda et al. 1992). This species is an opportunistic feeder and has eradicated many of Guam's native birds, mammals, and reptiles [see review by Fritts and Rodda (1998)]. The brown treesnake (BTS) Guam population peaked around 1985, possibly exceeding 100 snakes per ha (Rodda et al. 1992), coinciding with peak extinctions of many island bird species (Savidge 1987). As a keystone predator, the BTS has also altered plant and invertebrate diversity (Kahl et al. 2012a). Four solutions have been proposed for mitigating the damage caused by BTS on Guam: (1) control snakes in ports to prevent spread to other locations; (2) remove snakes in large areas to support localized species restoration; (3) greatly suppress snake populations island-wide; and (4) eradicate snakes completely (Rodda et al. 1998). At the smallest scale, interdiction measures have been in place at transportation ports and cargo since 1993, primarily relying on live trapping and searches (Stokstad 2013). Transportation represents a potential pathway for BTS to invade other islands and even southern locations of the continental United States where they could colonize (Kahl et al. 2012b). While interdiction methods have ostensibly prevented BTS spread, species restoration on Guam via localized removal, islandwide suppression, or eradication of BTS remains a primary goal. Broadcast delivery of toxic baits is still considered the principal tool capable of achieving this important objective.

Brown treesnakes are attracted to carrion (Shivik and Clark 1997). The USDA National Wildlife Research Center (NWRC) has successfully exploited this feeding behavior for BTS suppression programs by using dead neonatal mice (DNM) for the delivery of a highly effective toxicant (Savarie et al. 2001). In a recent study, snake activity in a 6-ha forest was reduced by more than $80 \%$ through aerial baiting (Clark and Savarie 2012). Despite these successes, alternatives to DNM have been actively pursued for the past 15 years. Among the undesirable characteristics of DNM are: cost (about $\$ 0.60$ each), handling requirements (must be shipped and maintained frozen until applied in the field), and longevity (effective field life of only 4 or 5 days). An artificial bait matrix that is less expensive, can be stored at room temperature before application in the field, and has a longer field life would be more efficient for operational use. Ultimately, alternatives to DNM as lures in bait devices have been difficult to identify because the sensory attributes of DNM are not easily replicated with non-prey food items. Another significant hindrance to development of effective lure materials is the testing methodology. Results with captive snakes do not always predict results in the field, while field testing is not conducive to the repetitive nature of screening candidate stimuli.

Numerous DNM substitutes have been tested in the past decade $\left(\right.$ Spam $^{\circledR}$, chicken, shrimp, pork, to name just a few), however, no processed human food items were found to be as attractive as actual prey items such as DNM, quail chick, or gecko (Savarie and Clark 2006). A simple approach of grinding whole mouse carcasses and producing "meatballs" was attempted, but these were taken at only one fifth the rate of intact DNM (Jojola-Elverum et al. 2001). Similarly, DNM were taken three times more often than untreated beef (USDA-APHIS-WS-NWRC, unpublished data). However, treatment of beef with DNM extracts caused beef baits to be accepted at rates similar to intact DNM.

Taken together, available evidence suggests that complex stimuli are needed to mimic the signals of DNM. While volatile compounds may serve as food cues from a distance, other chemical signals must be required to satisfactorily identify lures as prey. It is likely that both volatile and nonvolatile signals are present in DNM and must be present in any alternative. In fact, efforts to fractionate complex stimuli into simple components have the undesirable effect of reducing attractiveness of prey odors (Clark 1997). Proteins and lipids (fats) present in the skin may serve as the substrate that yields both volatile and nonvolatile cues via bacterial decomposition. Protein 
hydrolysis and lipid oxidation produce volatile odors (sulfides and aldehydes from proteins and lipids, respectively), while at the same time producing smaller proteins and peptides of low volatility. While often not detectable to humans, peptides can be detected by animals equipped with an auxiliary olfactory system. The vomeronasal organ (VNO) is the primary structure of the auxiliary olfactory system. While absent in humans, many animals, including rodents, have clearly defined VNO capable of detecting large proteins (Brennan and Kendrick 2006). Though not explicitly studied in BTS, the role of the VNO in foraging behavior has been demonstrated in garter snakes (Jiang et al. 1990; Liu et al. 1999; Luo et al. 1994).

The cost savings associated with replacing DNM can be significant, as are potential applications which could utilize a DNM surrogate (i.e. large-scale bait distribution, interdiction trapping programs, rapid response scenarios, and protection of rare natural resources areas such as swiftlet caves). The overall goal of this research was to identify an artificial bait to replace DNM. A primary objective was to avoid a reductionist approach and evaluate complex stimuli that best mimicked the sensory attributes of DNM. As such, the initial approach was to retain bait complexity while replacing DNM with skin material that could be obtained in greater quantity. The sensory qualities of several alternatives were assessed using conditioned taste aversion paradigm and a field test was conducted with the best candidate. Upon failure of this approach, a "bottom-up" approach utilizing chemical analyses of DNM skin was applied to construct an artificial DNM alternative from various sources of triglycerides. Finally, a series of experiments were conducted to identify the most promising delivery vehicle to present the artificial mixture.

\section{Materials and methods}

\section{Rat bioassay}

Three sources of animal protein were obtained for initial evaluation as potential alternatives for DNM. A conditioned taste aversion (CTA) generalization experiment was conducted 24 January to 10 February 2012 with rats to determine which of these sources most closely approximated the chemosensory attributes of DNM skin. Fetal pig carcasses of early (80-96 days) and late (113-124) gestational periods were obtained from Nebraska Scientific (Omaha, NE). Culled chick carcasses (0-2 days post-hatch) were obtained from a commercial hatchery. Neonatal mice carcasses were purchased from Noble Supply and Logistics (Rockland, MA). Skins were removed from all carcasses and pulverized in small batches using a nitrogen cooled mill (Spex SamplePrep, Metuchen, $\mathrm{NJ})$.

Twenty-four male Sprague-Dawley ${ }^{\circledR}$ rats (22-26 days old) were purchased from Charles River (Stone Ridge, $\mathrm{NY}$ ) and individually maintained in $35 \times 30 \times 16 \mathrm{~cm}$ rodent boxes with wire cage tops. Teklad Rodent Diet 8604 (Harlan, Madison, WI) was provided ab libitum while not on test, but overnight restricted when test baits were offered. Water was provided ad libitum. For test acclimation, each subject received a single acclimation diet cube (Table 1; see supplemental material for diet recipes) in a covered food dish placed in the cage for $2 \mathrm{~h}$ in the morning following overnight food restriction. Diets were weighed before and after placement in the cage and individual subject intakes were determined by difference. After 4 days, subjects were stratified by mean intake for assignment into one of four treatment groups such that mean diet intake and standard deviation were similar among the groups.

For the conditioned aversion test, diets were adulterated with homogenized DNM skin. All subjects were provided a single cube of the aversion diet for $2 \mathrm{~h}$ following overnight food restriction. Consumption of the aversion diet was followed immediately with an i.p. injection of a $30 \mathrm{mg} / \mathrm{mL}$ lithium chloride $(\mathrm{LiCl})$ solution (in sterile water) such that the dose was $150 \mathrm{mg} / \mathrm{kg}$ (requiring a $625-850 \mu \mathrm{L}$ injection, depending on body mass of the subject). Drugs or toxins that cause emetic malaise shortly after ingestion can be very effective in producing aversions to associated foods (Garcia et al. 1985). $\mathrm{LiCl}$ is commonly used for this purpose in CTA experiments (Riley and Freeman 2004). Basal chow was provided $4 \mathrm{~h}$ later and removed again overnight for 4 days of preference testing.

Preference tests were conducted by offering rats the test diets adulterated with test proteins according to treatment group assignment. Test diets were prepared with early gestational pig skin, late gestational pig skin, chicken embryo skin, or DNM. Each test diet was prepared in two batches: with and without red food 
Table 1 Test diet and bait designations for all experiments

\begin{tabular}{|c|c|c|}
\hline Diet/bait & Experiment(s) & Test substance \\
\hline Acclimation & Rat bioassay & None \\
\hline Aversion & Rat bioassay & Neonatal mouse skin \\
\hline Early pig & Rat bioassay & Early gestational fetal pig skin \\
\hline Late pig & Rat bioassay & Late gestational fetal pig skin \\
\hline Chick & Rat bioassay & Chicken embryo skin \\
\hline Alternative & Rat bioassay & Hydrolyzed casein \\
\hline DNM & Experiment $1,2,3,4$ & Dead neonatal mouse carcass \\
\hline Pig wrap & Experiment 1 & Late gestational fetal pig skin \\
\hline Pig tablet & Experiment 1 & Late gestational fetal pig skin \\
\hline Pig gum & Experiment 1 & Late gestational fetal pig skin \\
\hline ARASCO & Experiment 2 & Arachidonic single cell oil \\
\hline Poultry fat & Experiment 2 & Poultry fat \\
\hline Mouse butter & Experiment 2 & Mixture of triglycerides \\
\hline Complete & Experiment 2 & Mouse butter, collagen, mouse urine \\
\hline MB lizard & Experiment 3 & Mouse butter \\
\hline $\mathrm{MB}+$ lizard & Experiment 3 & Mouse butter, tofu, Roquefort \\
\hline MB cube & Experiment 3, 4 & Mouse butter \\
\hline $\mathrm{MB}+$ cube & Experiment 3 & Mouse butter, FOCUS, Roquefort \\
\hline ARASCO cube & Experiment 4 & Arachidonic single cell oil \\
\hline EPO cube & Experiment 4 & Evening primrose oil and other triglycerides \\
\hline
\end{tabular}

coloring so that diets could be visually discriminated when recovered from the cages. An alternative diet was the other diet available in two-choice tests. The alternative diet contained hydrolyzed casein instead of the test protein and was also prepared in two batches (i.e. with and without red food coloring).

Following overnight food restriction, six subjects in each treatment group received a test diet cube and an alternative diet cube such that one cube was red and the other was natural. Color was counterbalanced within each treatment (for three subjects the test diet was red and the alternative was red for the other three) and presentation of the colors (left, right) was alternated daily. Intake of both diets was determined after $2 \mathrm{~h}$ and preference scores were calculated: mass of test diet consumed divided by total consumption of both diets. The preference test was repeated three more times for a total of 4 days. Preference scores were analyzed by repeated measures analysis of variance (ANOVA) with treatment (protein source) the between-subjects effect and day and treatment $\times$ day the within-subjects effects. Residual plots were generated to evaluate ANOVA assumptions.

\section{Field bioassays}

Field testing of baits was conducted near Tarague Beach, Guam following the methods of JojolaElverum et al. (2001). Briefly, baits were placed in $30 \mathrm{~cm}$ polyvinyl chloride (PVC) tubes $(5.1 \mathrm{~cm}$ diameter) which were suspended in shrubs 1.5-2 $\mathrm{m}$ off the ground. Bolts were mounted at both ends of the tube such that the face of both openings was bisected by the bolt (making it difficult for crabs to access the test baits). Five pairs of transects were employed, each with 24 or 25 devices (for experiments 1, four baits were tested with 24 tubes per transect; for experiments 2, 3, and 4, five baits were tested with 25 tubes). Transect pairs were located on opposing sides of roads and the five transects were themselves separated by at least $50 \mathrm{~m}$. Baits were placed in a randomly-determined (by transect) repeated order (e.g. A-B-C-D-AB-C...) such that replicate test baits were not placed in adjacent tubes. Transects were walked daily by trained personnel for at least 6 days (test period differed among experiments). Tubes were examined for the presence (or absence) of the bait and the outcome was 
recorded. Missing baits were not replaced. Disappearance data were subjected to Kaplan-Meier failure analyses and Kruksal Wallis tests of ranked failure (disappearance day ranked within transect) with transect and treatment as fixed effects.

\section{Experiment 1}

The first field trial was conducted 10 April to 25 April 2013 to evaluate several presentations of late fetal pig skin (Table 1). Three test baits (prepared at NWRC Fort Collins, CO) were employed in the trial along with DNM as a positive control (see supplemental materials for bait recipes). The pig wrap bait consisted of fetal pig skin wrapped around a gum core. The pig tablet bait was prepared with ground fetal pig skin. The third test bait, pig gum, was prepared from skin extract. All test baits were vacuum-packed and maintained frozen for delivery to Guam. Bait disappearance was monitored for 12 days as described above.

\section{Experiment 2}

Various triglyceride mixtures were applied to pieces of sea sponge for this experiment conducted 03 December to 17 December 2013 (Table 1). Four different triglyceride mixtures and DNM (positive control) were tested: Arachidonic Acid Single Cell Oil (ARASCO $^{\circledR}$; DSM Nutritional Products, Columbia, MD), poultry fat (Pet Food Grade, Valley Proteins Inc., Fayetteville, NC), mouse butter (a triglyceride mixture which mimicked the fat profile of DNM skin), and a complete bait consisting of mouse butter, collagen, and mouse urine (see supplemental materials for bait recipes).

All test baits were prepared at the NWRC laboratory (Fort Collins, CO), vacuum-packed, and maintained frozen for delivery to Guam. Due to concerns that the sponge baits would not remain in the delivery tubes (low mass of sponge was subject to displacement by moderate winds), a single piece of strapping tape was placed across both openings of the tubes (below the bolts) such that the lower third of both ends was blocked by the tape. In addition to monitoring bait disappearance for 10 days, tape displacement was recorded as evidence of bait investigation.

\section{Experiment 3}

Food products and mouse butter were incorporated into unique delivery devices in Experiment 3, conducted 27 August to 4 September 2014 (Table 1). Soft plastic lizards (4"; Zoom Bait Company, Bogart, GA) were coated with liquefied mouse butter (MB lizard) or mouse butter, tofu, and Roquefort cheese (MB+ lizard).

MB cube baits were prepared from processed canned meat $(1.3 \times 1.3 \times 2.5 \mathrm{~cm}$ cubes $)$ coated with liquefied mouse butter. The $\mathrm{MB}+$ cube bait was similarly prepared with mouse butter, a cellulose termite attractant known to yield significant quantities of carbon dioxide when inoculated with fungi, bacteria, or yeast (FOCUS; Ensystex Inc., Fayetteville, NC), and Roquefort cheese. All test baits (including DNM as positive controls) were vacuum-packed and maintained frozen for delivery to Guam and employed in a 6-day field test.

\section{Experiment 4}

The final field trial was conducted 2 February to 17 February 2015. Test baits included cubes coated with mouse butter (MB cube), ARASCO ${ }^{\circledR}$ (ARASCO cube), or a mixture utilizing evening primrose oil (Sigma-Aldrich Co., St. Louis, MO) as a source of trilinolein (EPO cube). All test baits (including DNM as positive controls and untreated meat cubes as negative controls) were vacuum-packed and maintained frozen for delivery to Guam and employed in an 11-day field test.

\section{Stability testing}

Preliminary assessments of bait stability were made in the laboratory by subjecting baits to the environmental conditions anticipated at Guam. Test baits were placed in a controlled environmental chamber (Model E7/2; Controlled Environments Limited, Winnipeg, Canada). The unit was programmed to simulate a $24 \mathrm{~h}$ night/day cycle, varying between 21.5 and $30{ }^{\circ} \mathrm{C}$ with a constant $80 \%$ relative humidity and a fluorescence and incandescence photoperiod cycle programmed to vary from zero (night) to the maximum $100 \%$ output (day). Baits were observed daily for discernible visual changes such as desiccation, 
shrinkage, cracking, fungal growth, swelling, bloating, and rupture. Olfactory assessment was used to signal non-visual changes and decomposition products (putrefaction).

\section{Chemical analyses}

Fatty acid profiles of DNM skin and ARASCO ${ }^{\circledR}$ were determined by gas chromatography/mass spectrometry. Cryogenically homogenized DNM skin samples were extracted using a modified Folch extraction. Chromatographic analyses of fatty acids (as methyl esters) were conducted by gas chromatography mass spectrometry (see supplemental materials for procedures).

Various bait components and animal proteins were also subjected to headspace analyses followed by gas chromatography/mass spectrometry (see supplementary materials for procedures). In this technique, volatile compounds present in the vapor phase above a sample in a closed container are collected for chromatographic analysis. Resulting chromatograms were qualitatively evaluated to determine which materials yielded volatile compounds common to DNM.

\section{Results}

\section{Rat bioassay}

Preference scores of rats conditioned to avoid the flavor of DNM skin varied according to day $(p<0.0001)$, treatment $\times$ day $(p=0.0062)$, but not treatment $(p=0.1055)$. Preference scores varied wildly, resulting in no differences $(\alpha=0.05)$ among the four treatments on day 1. Only DNM (aversion diet) and late pig diet preference scores were statistically less than 0.5 (the measure of indifference between the two diet choices). On day 2, only the late pig preference score was similar to the aversion diet (DNM), whereas on days 3 and 4, all three test protein diets were highly preferred (preference scores greater than 0.5). Examination of the gas chromatograms indicated that late gestational pig skin had the most similar volatile profile in comparison to DNM (Fig. 1). As a result of these findings, the first field experiment employed novel baits prepared with late gestational pig skin.

\section{Experiment 1}

Pig wrap, pig tablet, and pig gum baits were tested in an environmental chamber for 14 days. All three baits exhibited a higher level of stability in comparison with the dead neonatal mouse (DNM) control. Specifically, the wrapped and gum baits desiccated over time while the tablet remained unchanged. By comparison, the DNM decomposed and putrefied by day 2 or 3 as indicated by a green coloration of the abdomen, followed by swelling, seepage, odor generation, and eventual rupture of the DNM carcass.

Disappearance rates of test baits differed among treatments in the field $(p<0.0001)$. Based on ranked failure data, results were similar among all transects and preference for bait types followed the order $\mathrm{DNM}>$ pig wrap $>$ pig tablet $=$ pig gum. Only $30 \%$ of pig wrap baits were removed; while $82 \%$ of DNM were taken.

\section{Experiment 2}

Chemical analyses demonstrated that the lipid profile of mouse butter closely matched the target of DNM skin and indicated that $250 \mathrm{mg}$ of the mixture yields a lipid abundance equivalent to a single DNM (Fig. 2). Qualitative evaluation of the chromatograms resulting from headspace analysis of mouse butter further indicated presence of many of the volatile lipid oxidation products observed in headspace analysis of DNM.

Baits prepared with sea sponge were evaluated in the environmental chamber over 3 weeks. Mouse butter was stable for the evaluation period and no bacterial or fungal decomposition was evident. However, disappearance rates of test baits in the field trial were extremely poor. Although $82 \%$ (43 of 50) of DNM were taken over the 10 day field trial, only three test baits $(1.5 \%)$ were removed from the bait tubes. However, visitation rates were much greater. Approximately $40 \%$ of all test bait tubes (excluding DNM) were visited-as evidenced by collapse of the tape placed across the tube openings. The majority of these visits were assumed to be snakes, as the bolts placed at the ends of bait tubes limit access by many non-target species.

\section{Experiment 3}

Headspace analyses of plastic lizards indicated they were contaminated with organic solvents, likely from 
Fig. 1 Chromatograms resulting from headspace analyses of dead neonatal mouse (DNM; dotted line) and late gestational pig (solid line) skins. Response for DNM has been magnified $\times 5$ for comparison

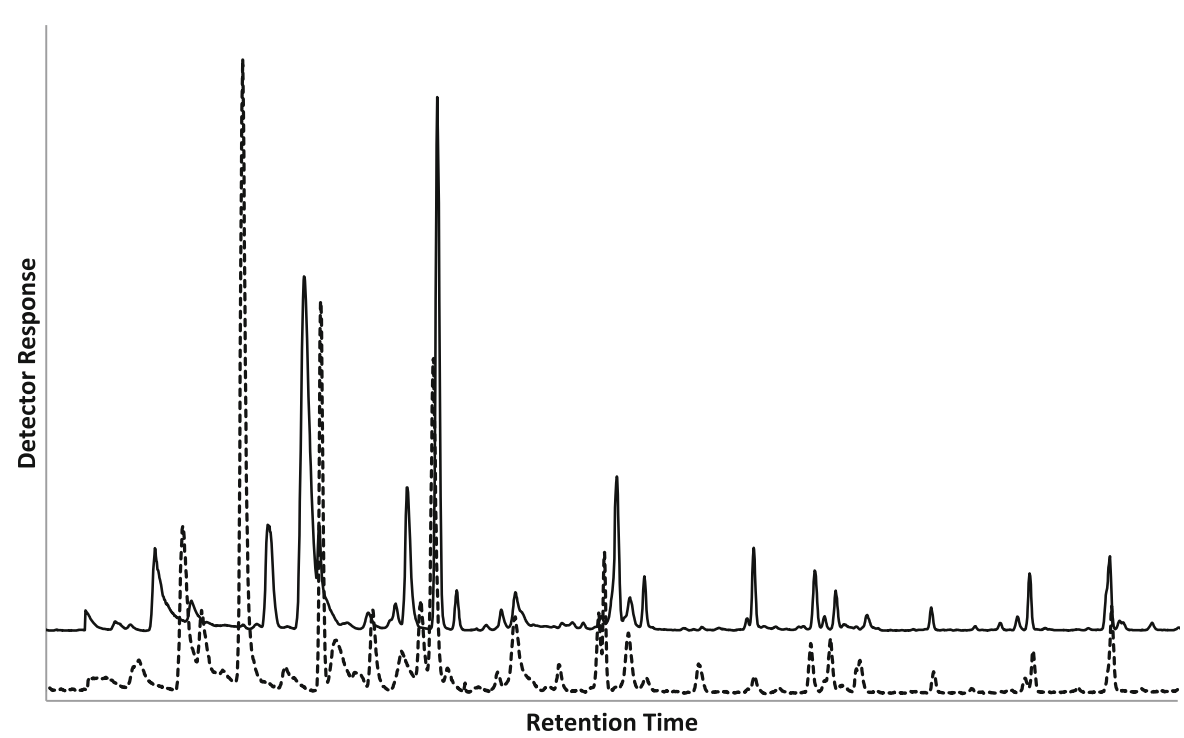

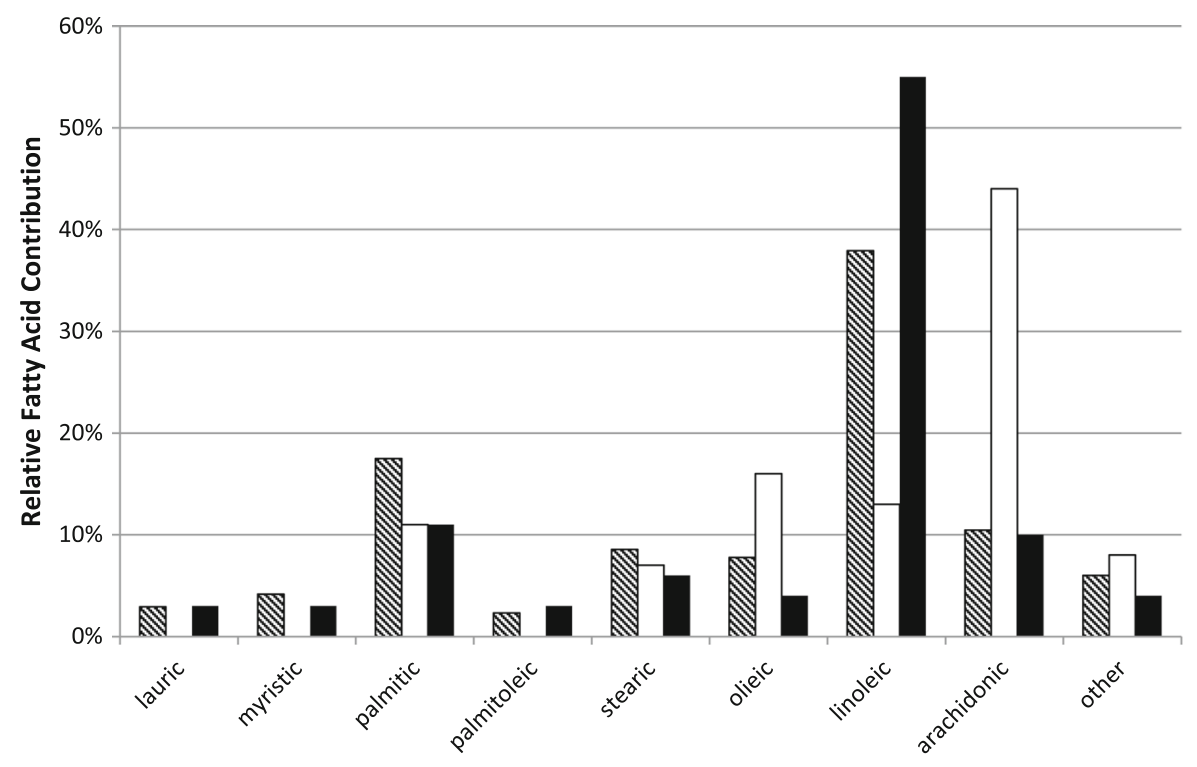

Fig. 2 Distribution and abundance of fatty acids identified in extracts of dead neonatal mouse skin (diagonal bars), Arachidonic Single Cell Oil (ARASCO ${ }^{\circledR}$; white bars), and artificial

the manufacturing process. Cleaning dramatically reduced these residues. Analysis of various cultured cheeses indicated that feta was not suitable as a bait component because of a high content of organic acids indicative of advanced aging (acetic, butyric, and hexanoic in particular). Roquefort had an interesting mix of oxidation products common to DNM volatiles, mouse lipid mixture (mouse butter; black bars) as determined by gas chromatographic-mass spectrometry analyses of hydrolysates

except the concentrations were at least two orders of magnitude greater than DNM or mouse butter. The termite attractant, FOCUS, produced significant quantities of ethanol upon fermentation; and, presumably, associated carbon dioxide (which co-elutes with the observed ethanol). Tofu exhibited some interesting oxidation products (near the same abundance as DNM 
and mouse butter), while processed meat also had some of the lipid oxidation products found in the other ingredients.

Disappearance rates of test baits in the field differed among treatments $(p<0.0001)$. Disappearance of DNM was very high (94\%) and followed the typical pattern with highest removal in the first few days (Fig. 3). Only one lizard bait was removed (MB+ lizard, treated with mouse butter, tofu, and Roquefort cheese). Snake acceptance of processed meat treated with mouse butter, FOCUS termite attractant, and Roquefort cheese $(\mathrm{MB}+$ cube) was similarly poor (13\%). However, processed meat treated with mouse butter (MB cube) demonstrated significant acceptance with removal of $60 \%$ of these baits.

\section{Experiment 4}

Following 1 week in the environmental chamber, untreated meat cubes were covered with fungal colonies (green and black spots). In contrast, cubes treated with ARASCO ${ }^{\circledR}$ were devoid of any fungal growth or obvious deterioration for the full 35 day stability trial. Similar stability was noted in the field where most remaining DNM were decomposed by day 5 or 6 , while mouse butter-treated meat cubes appeared to maintain the triglyceride coating better than the EPO or ARASCO ${ }^{\circledR}$ baits.

Disappearance rates of test baits differed among treatments $(p<0.0001)$. Removal of DNM was high
(82\% overall), but not as many DNM were removed in this experiment as compared to Experiment 3, despite the longer duration of Experiment 4. Acceptance of MB cubes (48\%) was much greater than EPO cubes $(26 \%)$, ARASCO cubes $(14 \%)$, or untreated meat cubes $(14 \%)$. In contrast to Experiment 3, removal of mouse butter baits was nearly constant across the 12 day experiment (Fig. 4).

\section{Discussion}

Past research of alternatives to DNM had followed three approaches: (1) testing of food products thought to be indicative of mammalian tissues; (2) transfer of DNM extractives to easier-to-use substrates; and/or (3) utilization of volatile signals identified in DNM. The goal of the present research was to systematically identify a suitable substitute for DNM such that the substitute was widely available and acceptance by BTS was similar. Nearly two decades of research had failed to identify a suitable alternative. Past field experiments demonstrated that bait removal data exhibited a tri-modal distribution. Many bait types are unattractive to BTS and result in less than $5 \%$ acceptance (Savarie and Clark 2006). Several bait types (largely consisting of animal tissues or commercial products containing animal tissues) are removed from tubes in the 20-35\% range. Removal rates of mice and baits derived directly from mice
Fig. 3 Summary of dead neonatal mouse (DNM) removal from bait tubes over four field experiments. Overall DNM take was $82 \%$ in Experiment 1 (dotdash); $82 \%$ in Experiment 2 (dot-dot-dash); $94 \%$ in Experiment 3 (short dash); and $82 \%$ in Experiment 4 (long dash). The composite mean take rate is fitted to a logarithmic function (solid gray line)

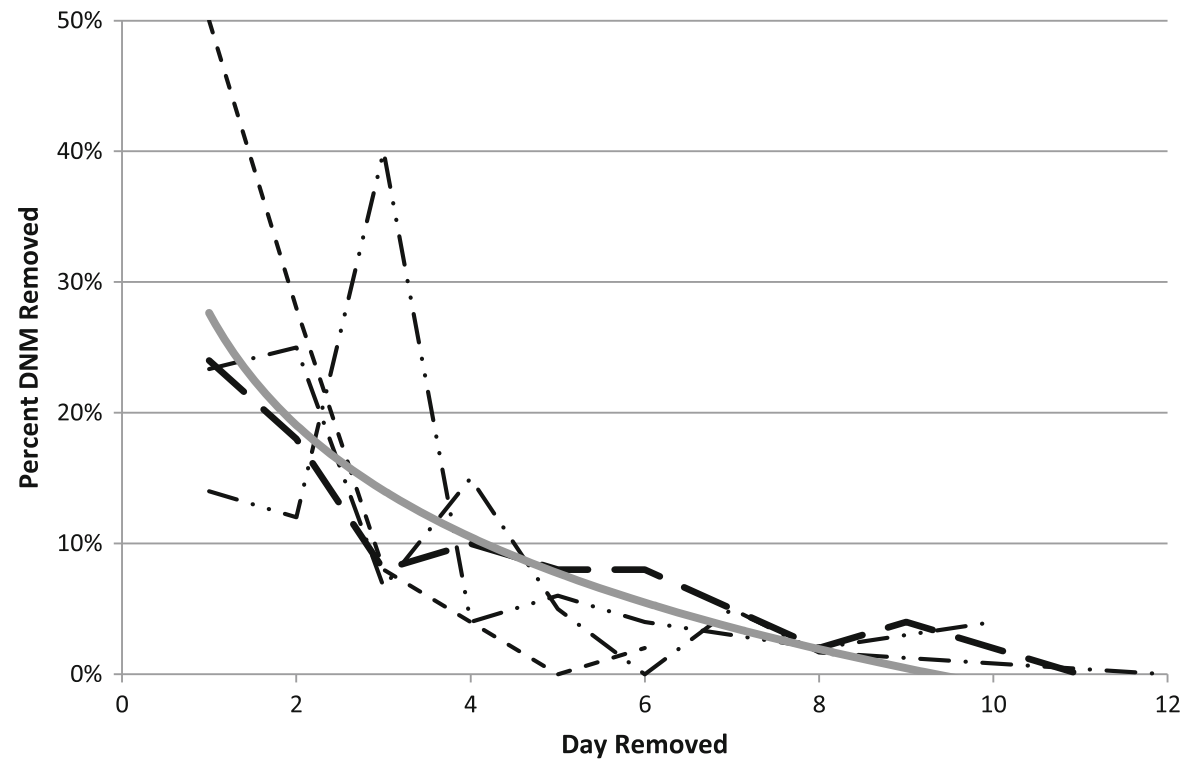


Fig. 4 Removal of processed meat baits treated with mouse butter artificial lipid mixture in Experiments 3 (short dash) and Experiment 4 (long dash) and composite dead neonatal mice (DNM; solid gray line) across all four field experiments (fitted to logarithmic function). Average DNM take was $85 \%$ over the four experiments while test bait removal was $60 \%$ in Experiment 3 and $48 \%$ in Experiment 4

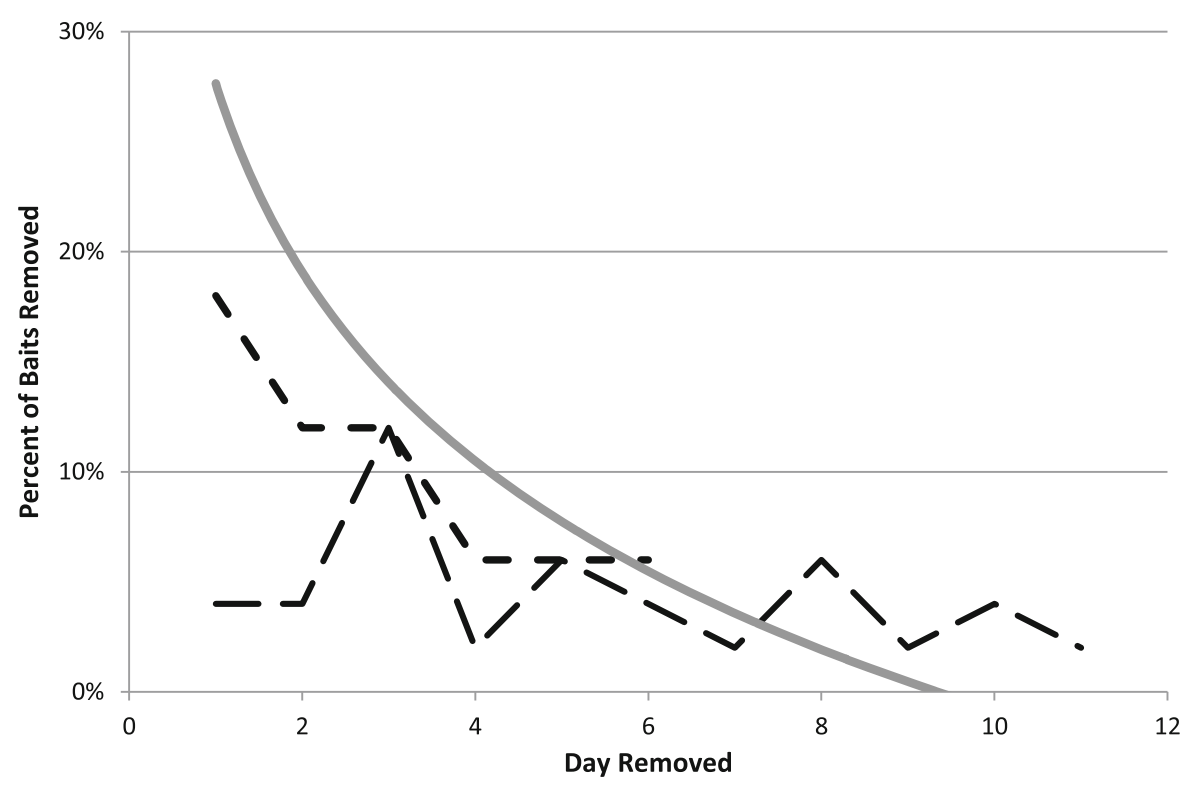

typically range from 70 to $90 \%$ (Savarie et al. 2001; Jojola-Elverum et al. 2001). This is the first study to yield bait acceptance approaching that of DNM without directly employing mouse components. Furthermore, the field performance of canned meat-based baits indicates that processed products may yield baits with extended field life relative to DNM that are rarely taken by snakes after the fifth day of deployment.

In CTA experiments, integration of flavor (food components) and postingestive consequences of the eating the food (e.g. malaise caused by administration of $\mathrm{LiCl}$ ) may lead to avoidance of the food associated with lithium toxicosis (Provenza et al. 1992). In this experiment, a single dose of $\mathrm{LiCl}$ paired with the novel DNM diet did not promote a strong aversion as evidenced by the preference score rapidly reaching 0.5 -indicating indifference. Nonetheless, only late gestational pig skin appeared to share some chemosensory attributes with DNM as indicated by similar preference scores on both days 1 and 2. Furthermore, visual inspection of the chromatographic data suggested that late gestational pig skin shared a similar volatile profile as DNM skin (Fig. 1). Thus, experiment 1 focused on the use of late gestational pig skin in a field trial with free-ranging BTS on the island of Guam. Although these formulations were fairly stable, baiting efficacy was extremely poor. A decision was made to forego the use of novel animal skins and focus on the lipid fraction of dead neonatal mice.
The targeted triglyceride profile (Fig. 2) was achieved by locating a novel source of food-grade triglycerides. Arachidonic Acid Single Cell Oil (ARASCO $^{\circledR}$; DSM Nutritional Products, Columbia, MD), a mixture of several triglycerides, was easily supplemented with other triglycerides to match the desired composition. Sea sponge was identified as a potential bait vehicle to transport the lipid mixture and yield optimum bait geometries (conducive to the mechanical delivery system). Results of the field study demonstrated that sea sponge was a good substrate for presentation of lipid-related food cues, but a poor substrate for promoting consumption. Although removal rates of artificial baits were extremely low, visitation into the tubes was high among all baitssuggesting that the artificial mouse lipid mixture generates important cues that draw snakes to within inches of the bait.

The combination of processed meat and mouse butter yielded excellent acceptance in both Experiments 3 and 4. Visual inspection of baits during field deployment indicated that the processed meat was relatively resistant to spoiling, ant infestation, and mold in relation to DNM (spoilage, ants) and plastic lizards (mold). Poor acceptance of the lizard lures in experiment 3 may be attributed to heavy rains for the first few days of the field experiment when it was visually evident that applied treatments were "washed off". However, results suggest some components of 
the treatments remained adhered to the meat cubes and some of the treatments may have reduced acceptance by snakes. Specifically, differences in disappearance of meat cubes treated with mouse butter, FOCUS, and Roquefort cheese $(13 \%)$ versus cubes treated with only mouse butter $(60 \%)$ cannot be attributed to the effects of rain. The high magnitude of Roquefort volatiles and/or the distribution of these volatiles (e.g. organic acids) may have rendered baits prepared with Roquefort undesirable in the same manner that older DNM (greater than 3 or 4 days) become less acceptable to snakes.

Previous studies were unable to achieve greater than $50 \%$ acceptance of baits in field deployments except when DNM, DNM pelts, or DNM extracts were deployed (Clark 1997; Jojola-Elverum et al. 2001; Savarie and Clark 2006). Additionally, research with captive snakes demonstrated that DNM were preferred 2:1 over Spam ${ }^{\circledR}$ in pair-wise comparisons (Savarie and Clark 2006). Because results with captive snakes are rarely replicated in the field, it was not surprising that preference of DNM over untreated processed meat cubes was closer to 6:1 with free-ranging snakes. Experiment 4 further demonstrated that the artificial lipid mixture not only increased acceptance of the meat cubes, but also that the complex mixture was preferred over baits prepared with only ARASCO ${ }^{\circledR}$. Incorporation of EPO as a source of trilinolein reduced bait acceptance relative to the complete mouse butter formulation, despite being formulated with a similar fatty acid profile target. However, the EPO source was not analyzed and thus the triglyceride contributions may have varied from reported values (Application Note 59128, Restek Corp., Bellefont, PA) or in free fatty acids content relative to the triglycerides used to prepare mouse butter.

Snake free areas are currently being maintained to prevent snakes from leaving the island and protect resources on Guam. For this purpose, DNM are actively used for toxicant delivery (presented in bait tubes similarly to our field studies) and live mice are used in snake traps. These devices are employed around airfields, housing areas, electrical substations, and ports. Ideally, long-lasting artificial bait could replace both DNM for toxicant delivery and live mice for trap lures. Replacement would result in logistical and economic benefits for the entire snake management program. The artificial lipid mixture based on DNM skin triglycerides combined with a processed meat substrate promises to satisfy many of the desirable attributes of an artificial bait; namely: simple, long shelf life, extended field life, biodegradable, and efficacious. DNM are difficult to procure in large quantities and are not easily incorporated into automated bait packaging systems that are currently being developed for an automated aerial broadcast system. This automated system could be employed to promote large $(\sim 1000 \mathrm{ha})$ snake free areas or eradicate snakes island wide. Live mice are even more expensive than DNMs and require extensive maintenance. Replacing live mice with an effective artificial lure would make the current management program more cost effective and allow for greater program flexibility.

Baits fashioned with an artificial lipid mixture can be significantly cheaper than DNM, which cost $\$ 0.45-$ $\$ 0.60$ each (depending on the supplier). The unit cost of the artificial lipid components is $\$ 0.10$ (retail purchase of chemicals purchased in small quantities), while the retail cost of canned, processed meat is $\$ 0.04$ per bait unit. Assuming that a canned meat substrate can be constructed from rendered pig by-products (e.g. porcine meat and bone meal currently costs $\$ 478$ per metric ton) and the lipid components can be purchased at a cheaper bulk rate, the per unit cost of materials for an artificial bait may conceivably be less than $\$ 0.14$. Savings approaching $\$ 0.50$ per bait can be rather substantial considering the potential number of baits necessary in a suppression program. To achieve $80 \%$ reduction, Clark and Savarie (2012) used three consecutive applications of 37.5 baits per ha. With land area of approximately 54,000 ha, over two million baits would be required for each island-wide application.

Acknowledgments These studies were made possible through funding provided by the U.S. Department of Interior Office of Insular Affairs (Agreement 101580RU033) and U.S. Department of the Navy (MIPR\# N6274212MP00024) and generous access to Andersen AFB. The assistance of USDA-APHIS-WS staff located on the island of Guam was greatly appreciated; especially Daniel S. Vice (1970-2014), Assistant State Director for the Hawaii/Guam Program, who dedicated much of his career to the control and interdiction of invasive species. Spam ${ }^{\circledR}$ is a registered trademark of Hormel Food Corporation (Austin, MN). ARASCO ${ }^{\circledR}$ is a registered trademark of DSM Nutritional Products (Columbia, MD). We thank DSM Nutritional Products for providing a complimentary sample of ARASCO ${ }^{\circledR}$. Mention of specific trade names does not constitute endorsement by the US Department of Agriculture. 


\section{References}

Brennan PA, Kendrick KM (2006) Mammalian social odours: attraction and individual recognition. Philos Trans R Soc B Biol Sci 361:2061-2078

Clark L (1997) Responsiveness of brown tree snakes to odors. In: Mason JR (ed) Repellents in wildlife management. Colorado State University, Denver, pp 129-137

Clark L, Savarie PJ (2012) Efficacy of aerial broadcast baiting in reducing brown treesnake numbers. Hum Wildl Interact 6:212-221

Fritts TH, Rodda GH (1998) The role of introduced species in the degradation of island ecosystems: a case history of Guam. Ann Rev Ecol Syst 29:113-140

Garcia J, Lasiter PS, Bermudezrattoni F, Deems DA (1985) A general-theory of aversion learning. Ann N Y Acad Sci 443:8-21

Jiang XC, Inouchi J, Wang D, Halpern M (1990) Purification and characterization of a chemoattractant from electric shock-induced earthworm secretion, its receptor-binding, and signal transduction through the vomeronasal system of garter snakes. J Biol Chem 265:8736-8744

Jojola-Elverum SM, Shivik JA, Clark L (2001) Importance of bacterial decomposition and carrion substrate to foraging brown treesnakes. J Chem Ecol 27:1315-1331

Kahl SS, Henke Hall MA, Britton DK (2012a) Brown treesnakes: a potential invasive species for the United States. Hum Wildl Interact 6:181-203

Kahl SS, Henke SE, Hall MA, Litt AR, Perry G, Britton DK (2012b) Examining a potential brown treesnake transport pathway: shipments from Guam. Hum Wildl Interact 6:204-211

Liu JM, Chen P, Wang DT, Halpern M (1999) Signal transduction in the vomeronasal organ of garter snakes: ligand- receptor binding-mediated protein phosphorylation. Biochim Biophys Acta Mol Cell Res 1450:320-330

Luo YQ, Lu SJ, Chen P, Wang D, Halpern M (1994) Identification of chemoattractant receptors and g-proteins in the vomeronasal system of garter snakes. J Biol Chem 269:16867-16877

Provenza FD, Pfister JA, Cheney CD (1992) Mechanisms of learning in diet selection with reference to phytotoxicosis in herbivores. J Range Manag 45:36-45

Riley AL, Freeman KB (2004) Conditioned taste aversion: a database. Pharmacol Biochem Behav 77:655-656

Rodda GH, Fritts TH, Conry PJ (1992) Origin and population growth of the brown tree snake, Boiga irregularis, on Guam. Pac Sci 46:46-57

Rodda GH, Fritts TH, Perry G, Campbell EW III (1998) Managing island biotas: can indigenous species be protected from introduced predators such as the brown treesnake. Trans N Am Wildl Nat Resour Conf 63:95-108

Savarie PJ, Clark L (2006) Evaluation of bait matrices and chemical lure attractants for brown tree snakes. In: Proceedings of the 22nd Vertebrate Pest Conference, Berkeley, CA, 6 March 2006. University of California, pp 483-488

Savarie PJ, Shivik JA, White GC, Hurley JC, Clark L (2001) Use of acetaminophen for large-scale control of brown treesnakes. J Wildl Manag 65:356-365

Savidge JA (1987) Extinction of an island forest avifauna by an introduced snake. Ecology 68:660-668

Shivik JA, Clark L (1997) Carrion seeking in brown tree snakes: importance of olfactory and visual cues. J Exp Zool 279:549-553

Stokstad E (2013) Island of the snakes. Science 342:1166-1167 